\title{
Making Noise: Toronto Public Library's Local Music Project
}

\section{By Thomas Krzyzanowski}

The singer in a revealingly tight velour bear costume bounces around the stage, screaming hardcore rhymes to the delight of the young people in the crowd. Taking a cue from their enthusiasm, he throws himself onto their upstretched hands and proceeds to crowd surf for a couple of seconds before clambering back to the rest of the band to finish the set. It's par-forthe-course concert antics for Matt Collins, lead singer for Toronto punk-rap outfit Ninja High School. What's unusual about this particular display is that it's not taking place in a dive bar or a concert hall; rather, the boisterous crowd at this show is headbanging and pogoing in the traditionally staid confines of a public library branch.

The last few years have been exciting times for music fans in Toronto. New venues have appeared all over the city (some popping up seemingly overnight), and bands you might see playing for a handful of people at the back of a seedy bar can be headlining major international tours a scant few months later. Toronto's experience is a microcosm (albeit a significant one) of the Canadian popular music scene, which has been flooded over the past decade with talented performers in all genres, pushing their art in new directions and developing supportive communities both nationally and around the world.

The significance of this musical renaissance has not been lost on the staff at Toronto Public Library (TPL). Beginning in 2006, TPL has collected albums produced by artists working in and around Toronto. This Local Music Collection spans popular genres and styles, and includes artists ranging from garage bands releasing their first EP (extended-play single) to singers who have achieved relatively high levels of commercial and popular success. In 2010, the collection added its thousandth album to the library catalogue, and as of early 2013 , this figure has nearly doubled.

Much of the success of the Local Music program is due to the strong partnerships the collection has attracted. Two critical relationships that have maintained the program since its start are the library's connections with Soundscapes and Exclaim! magazine.

As one of Toronto's best independent music retailers, Soundscapes has an intimate knowledge of Canadian music that has been invaluable in helping us choose recordings for our collection. Acting as our earliest partner and principal vendor for the Local Music project, Soundscapes has 
helped us plan and build an exciting body of recordings featuring some of the best popular music the city has to offer.

As library staff members worked to get the program off the ground, they received a welcome call from the staff at Exclaim! magazine, who were eager to get involved in this strange new venture. Founded in 1991 by radio DJs from Ryerson's CKLN FM, and a leading authority on Canada's popular music scene, Exclaim! has relationships with local musicians that have been key in developing the library's collection and its associated events.

In addition to our partnerships with Exclaim! and Soundscapes, the Local Music collection has enjoyed fruitful relationships with other Canadian music industry organizations, including Blocks Recording Club, The Polaris Music Prize, and the Juno Awards.

While the Local Music program has been quietly enriching TPL's CD collection, the project's associated events have received far noisier attention. The collection was launched with two concerts in November 2006, hosted at the system's two largest libraries. The first, at the North York Central Library, was a revue of the members of Blocks Recording Club, and featured performances by Bob Wiseman, The Creeping Nobodies, Ninja High School, Hank, and Owen Pallett (at the time performing under the stage name Final Fantasy). Following this was a concert at the Toronto Reference Library with Greater Toronto Area bands Elliot Brood, Lal, The Great Lake Swimmers, The Old Soul, and Shad. The positive public response to these initial concerts encouraged the Local Music team to continue to plan events at local libraries, and out of this, the Make Some Noise series emerged.

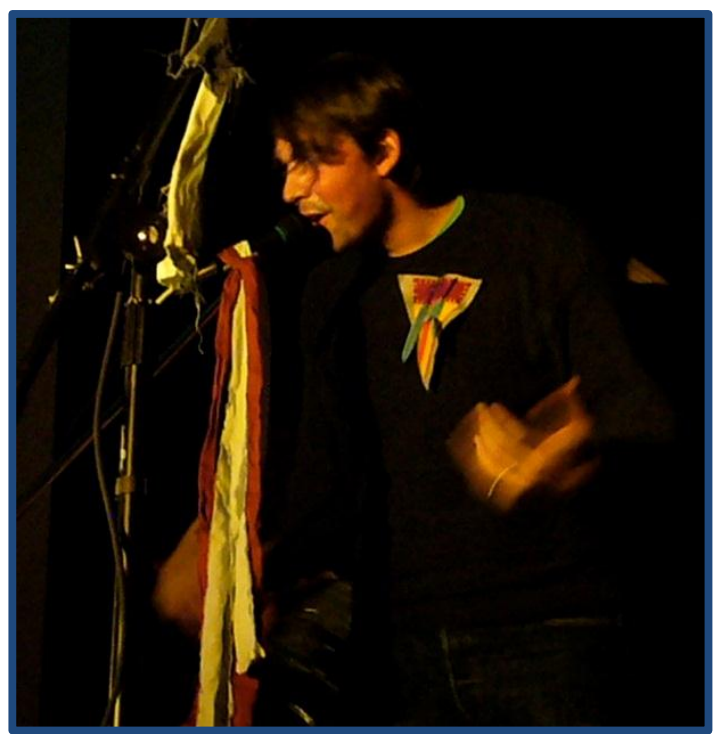

Bruce Peninsula at the North York Central Branch Make Some Noise, Nov. 7, 2009 Photo by Susan Kernohan

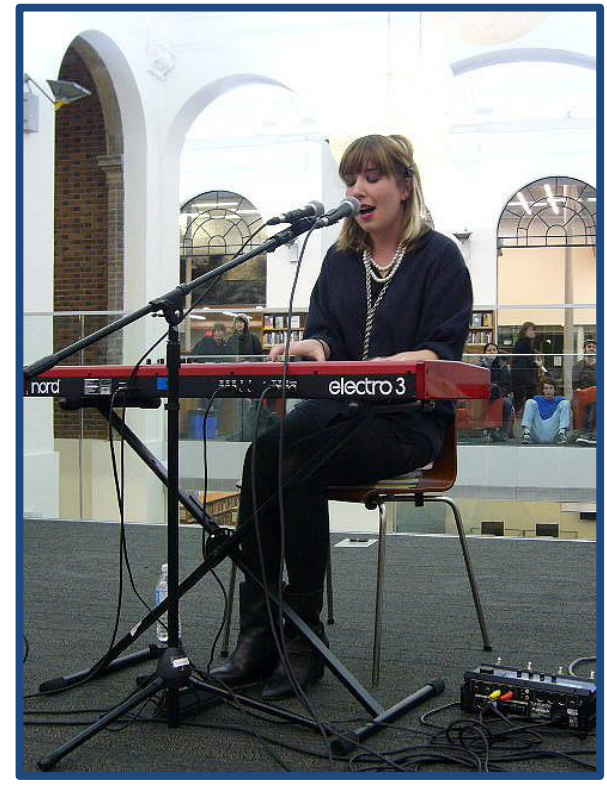

Katie Stelmanis at the Bloor/Gladstone Branch Make Some Noise, Nov. 20, 2009 Photo by Susan Kernohan 
Make Some Noise is a performance and workshop series that brings musicians, artists and members of the Toronto local music community into libraries around the city to share their varied talents (much in the way an author might visit a local library branch to do a reading from a new book). Over the years the library has hosted concerts by such wide-ranging acts as hardcore provocateurs Fucked Up, gothic folkists Timber Timbre, local fan favourites Ohbijou, and rising power-pop star Diamond Rings, to name but a few. The program has also included DJ workshops, music journalist Q\&As, and documentary video screenings to help foster a connection between our collections, local performers, and our users.

Make Some Noise events are always free and for all ages, and we encourage interested members of the public from all of Toronto's diverse communities to attend.

"Some of the most rewarding moments for us as organizers have involved seeing library visitors unexpectedly encounter local bands for the first time," says Make Some Noise originator Lisa Heggum. "We love it that we are providing a safe and welcoming space to experience innovative new music for people who might find it challenging to make it out to a traditional club or concert venue."

TPL has been further encouraged by discovering other library systems around North America that have started

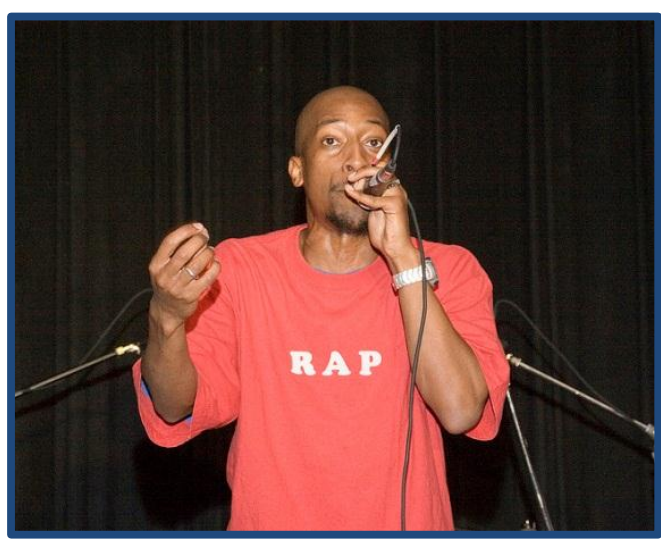

More or Les at the North York Central Branch Make Some Noise, Nov. 3, 2007 Photo by Susan Kernohan

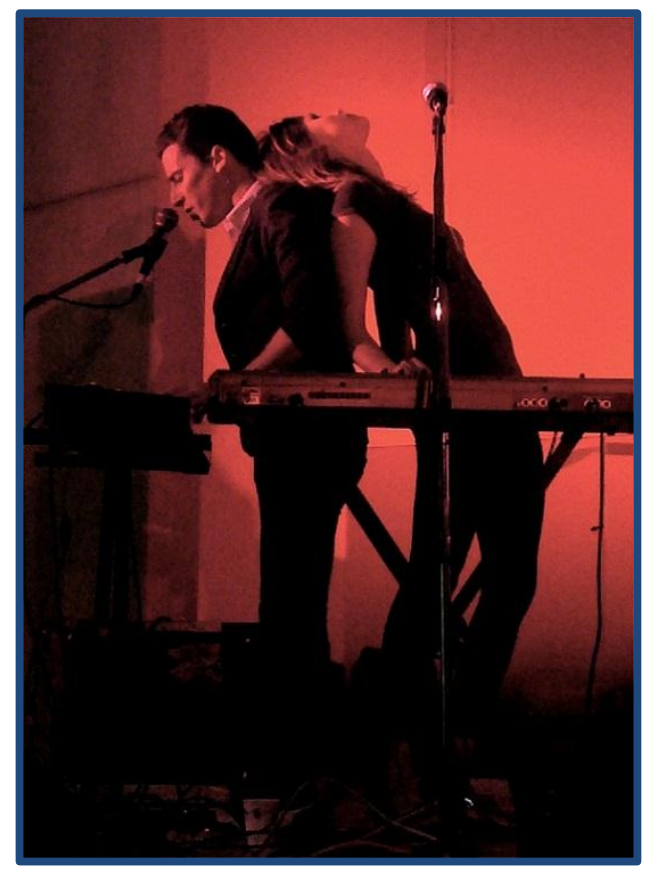

The Magic at the North York Central Branch Make Some Noise, Nov. 20, 2010 Photo by Susan Kernohan similar initiatives, either on their own or using TPL as a model.

The Guelph Public Library held a local music event in July 2011, and kindly credited TPL's Local Music program as an influence in their planning. The Greater Sudbury Public Library has also started inviting local musicians to play in their branches, and is building connections with media outlets and retailers to promote their efforts. Finally, south of the border, the lowa City Public Library (in a move perhaps divining things to come) has started an online, downloadable collection of recordings by local musicians, available for free to any card-holding member of their community. 
In 2010, Make Some Noise was recognized by the Ontario Library Association when they awarded the program with a Media and Communications Award for its innovations in promoting the Local Music Collection.

Through the Local Music Collection and Make Some Noise event series, the Toronto Public Library has developed important connections with one of the most exciting segments of the Canadian arts industry. TPL has also demonstrated its willingness to support local culture on its own terms: raucous, dynamic, frequently disorganized and occasionally controversial. Allowing the local music community to help determine the direction of the program has always been a guiding tenet and a major factor in its ongoing success.

We have created a collection and events series that appeal to demographic populations that historically have been difficult to draw into public library spaces. These people may not have seen the role for the public library in their lives. Providing the opportunity to stop by the library to hear a band play or to borrow the latest indie rock CD demonstrates TPL's commitment to serving these users alongside all of Toronto's many other faces. Moreover, it highlights the deeper cultural significance of the institution of the public library, and the value that our library system in Toronto places on creativity, intellectual exploration, inclusivity and community.

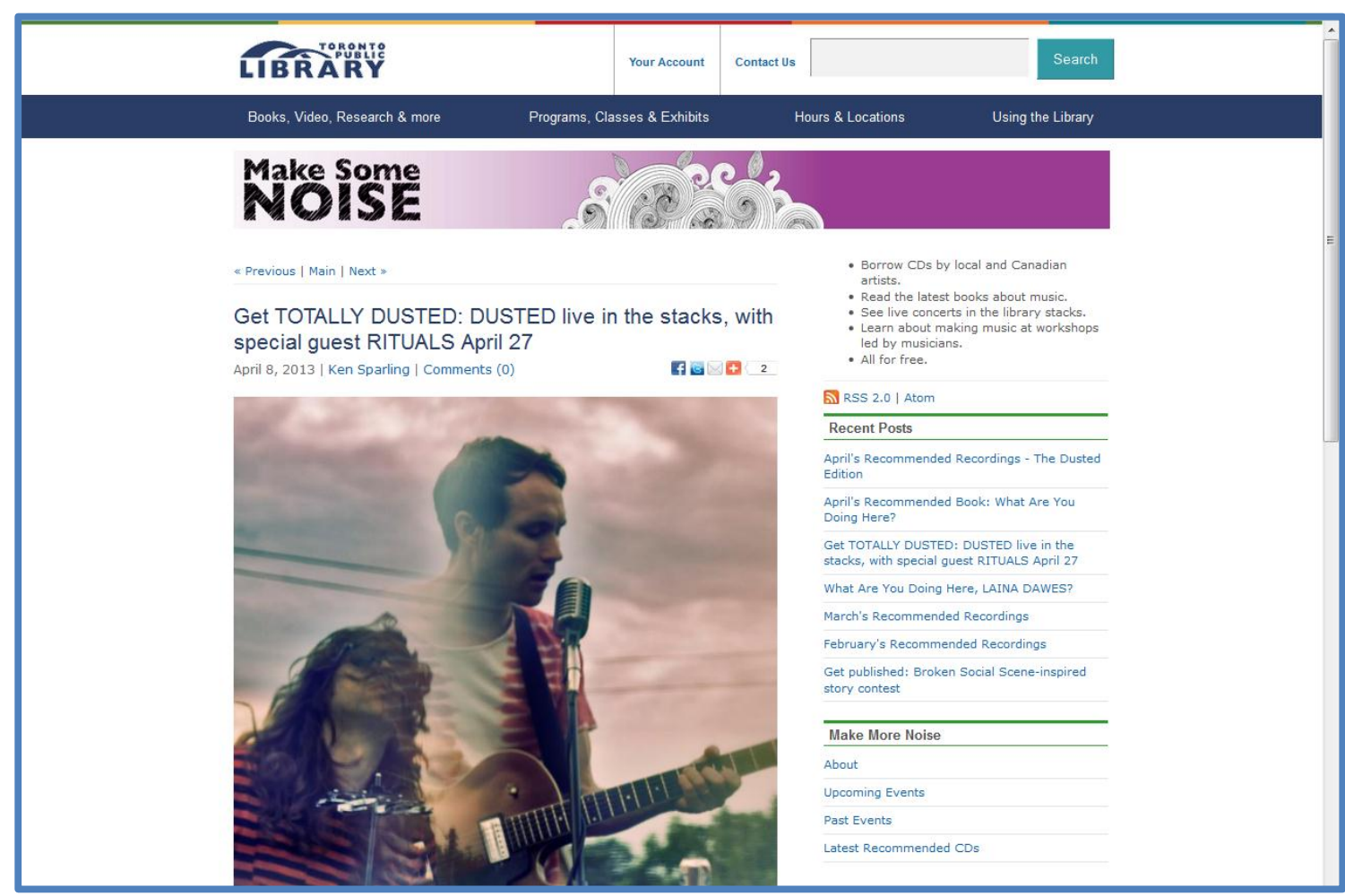

The Local Music program staff maintains a blog to share information about the collection and events. Find out more about the program by visiting www.torontopubliclibrary.ca/noise. 